Review article

\title{
Is the shielding effect of cholecalciferol in SARS CoV-2 infection dependable? An evidence based unraveling
}

\author{
Shaik Lahoor Basha, PharmD ${ }^{a}$, Sake Suresh, MD ${ }^{b}$, V.V. Ashok Reddy, MD ${ }^{c}$, S P Surya Teja, \\ $\mathrm{PhD}^{\mathrm{d}, *}$
}

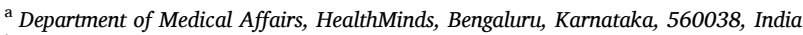

${ }^{\mathrm{b}}$ Department of General Medicine, Andaman \& Nicobar Health Services, Port Blair, 744104, India

${ }^{\mathrm{c}}$ Department of Emergency Medicine, Pushpagiri Institute of Medical Sciences, Tiruvalla, Kerala, India

${ }^{\mathrm{d}}$ Health Minds Consulting Pvt Ltd, Bengaluru, India

\section{A R T I C L E I N F O}

\section{Keywords:}

Cathelicidin

Latitude

Influenza

Pneumonia

Diabetes

Hypertension

\begin{abstract}
A B S T R A C T
Despite being announced as a global health concern and emergency in January by WHO, designing specific treatment for SARS-CoV-2 is still a summit yet to be conquered. Currently, many drugs are being tested in the clinical scenario and vitamins play a significant role in therapeutic management. Based on the available evidence, we postulate that maintaining normal vitamin $\mathrm{D}_{3}$ levels may reduce severity, mortality risk of COVID-19. This review elucidates the alarming need for randomized clinical trials to determine the role of vitamin $\mathrm{D}$ in patient prognosis in COVID-19 infection and on latitude bases epidemiological outcome.
\end{abstract}

\section{Introduction}

Vitamin D, a fat-soluble vitamin, has a crucial role in bone metabolism and calcium homeostasis. Vitamin D exists in two forms, namely, D2 (derived from plants) and D3 (cholecalciferol; derived from animals and humans). ${ }^{1}$ Dietary and sunlight assisted (Ultra Violet-B radiation) conversion of 7-dehydrocholesterol present in the skin to cholecalciferol is the primary sources of vitamin $\mathrm{D} .{ }^{[1]}$ The produced vitamin $\mathrm{D} 3$ or dietary vitamin $\mathrm{D}$ is metabolized to $25(\mathrm{OH}) \mathrm{D}$ in the liver and then to calcitriol in the kidneys which regulate the calcium levels by negative feedback mechanism with parathyroid hormone (PTH). ${ }^{2}$

Recent research indicates that vitamin D plays a significant role in inflammation, immunity, and host defense mechanisms; aids in the prevention of RTIs in terms of frequency and mortality. ${ }^{3}$ The vitamin D induces the production of antimicrobial peptides, such as cathelicidins (LL-37) and $\beta$-defensins and activates innate immunity partly by toxin neutralization and chemotactic action of antimicrobial peptides. ${ }^{4-6}$ Cathelicidins predominantly exhibit direct microbicidal activity against a spectrum of pathogens, including enveloped and nonenveloped viruses, gram-positive and gram-negative bacteria, and fungi. ${ }^{7}$ The anti-viral activity of LL-37 was verified by Barlow PG et al. in murine models and their research findings depicted that LL-37 decreased the viral replication of influenza A virus, elucidating anti-viral activity. ${ }^{8}$ In addition, Vitamin D also governs the activities of dendritic cells and macrophages, as well as the activation of Toll-Like Receptors (TLRs). ${ }^{9}$ This in turn leads to the expression of antimicrobial peptides and the subsequent eradication of the pathogens. ${ }^{10}$ In COVID-19 patients, a proliferation of both anti-inflammatory and pro-inflammatory cytokines has been observed in response to innate immune system provoked by SARS-CoV-2. ${ }^{11}$ In the case of adaptive immunity, the role of vitamin D has been widely established, where it exhibits a suppressive effect on $\mathrm{T}$ helper-1 cell proliferation and activation, in turn, produce interferon $\gamma$ and lead to macrophages activation. ${ }^{12}$ Hence, cholecalciferol modulates both the acquired and innate immune system. One in vitro study reported that interferons are responsible for acute lung injury during the late phase of the SARS-CoV pathology. ${ }^{13}$ A pro-inflammatory cytokine storms haven been identified in most severe cases of MERS-CoV and SARS-CoV. ${ }^{14,15}$ Vitamin D reduces the cytokine storm risk by decreasing the expression of pro-inflammatory cytokines. ${ }^{11}$ Hence, the effect of cholecalciferol on immune modulation for anti-viral protection cannot be ignored.

\section{Methods}

PubMed, MEDLINE, Embase, and ScienceDirect were searched to select all of the studies published in the last 10 years using a

\footnotetext{
* Corresponding author.

E-mail addresses: lahoorbasha@gmail.com (S. Lahoor Basha), spsuryateja50@gmail.com (S.P. Surya Teja).
} 
combination terms, such as vitamin D and COVID-19, 25(OH)D and COVID-19, vitamin D and respiratory tract infections, case fatality ratio and corona virus, vitamin D and sunlight, countries and latitudes, and vitamin D and immune system. Gray literature; published abstracts and recent updates on COVID-19 were obtained through searches of Centers for Disease Control and Prevention (CDC; https://www.cdc.gov/cor onavirus/2019-ncov/index.html) and ClinicalTrials.gov database, technical reports, and statistical reports. The search was restricted to publications in the English language. More than 500 articles were found, but only articles published in English, those related to our search criteria as well as those showing evidence-based data were included. Screening and review of articles were conducted in accordance with the Preferred Reporting Items for Systematic Reviews and Meta-Analyses (PRISMA) (Fig. 1).

Statistical analysis was done using software $\mathrm{R}$ version 3.6.0. Normality of the data was determined using the Shapiro-Wilk test. The continuous variables with normal distribution were presented as mean \pm standard deviation and compared using paired $t$-test. Mann-Whitney $U$ test was performed for variables without following a normal distribution. Odds ratio (OR) was used to measure the odds of COVID-19 mortality among lower $\left(<35^{\circ}\right)$ and higher $\left(>35^{\circ}\right)$ latitude countries. The correlation between case fatality ratio (CFR) and earth latitude of different countries was developed Spearman's correlation analysis. A $P$ value of $<0.05$ was considered statistically significant at $95 \%$ confidence interval.

\section{Age dependency of Vitamin-D in COVID-19 infections}

A high percentage of research states that elderly persons ( $\geq 60$ years) are at greater risk to develop vitamin D deficiency than children. Serum $25(\mathrm{OH}) \mathrm{D}$ levels tend to decline with age as aging reduces the skin's ability to produce cholecalciferol; less time outdoors and lower concentration of 7-DHC in the skin are being the key determinants of vitamin D deficiency. ${ }^{16,17}$ Moreover, pharmaceutical drug usage increases with age which reduce serum $25(\mathrm{OH}) \mathrm{D}$ levels through the activation of the pregnane- $X$ receptor. ${ }^{18}$ Such drugs constitute antineoplastics, antiepileptics, antibiotics, antihypertensives, anti-inflammatory agents, endocrine drugs, antiretrovirals, and some herbal medicines. ${ }^{18}$ All these factors have a major impact on pandemic (COVID-19) as CFRs are in direct proportion with age. ${ }^{19}$ Daneshkhah et al. demonstrated that the age-specific CFR of COVID-19 was highest in European countries with a greater incidence of severe vitamin D deficiency, Italy, France, and Spain. ${ }^{20}$ Data with these characteristics are missing (or under-reporting) for the majority of the cases and it is quite difficult to demonstrate age-sex specific CFR of COVID-19. Bulut et al. reported that $83 \%$ mortality cases in Italy were aged $\geq 70$ years old and also a similar pattern was observed in South Korea and the United states as well. ${ }^{21}$ Older people are the more vulnerable group to COVID-19 in countries, such as Sweden (70-90 years), Czech Republic ( $>75$ years), Hungary (66-88 years), Spain (70-79 years), Netherlands ( $>75$ years), Belgium ( $80-89$ years), Switzerland ( $>80$ years), Poland (75-77 years), Ukraine (60-69 years), and United States ( $>7$ years). ${ }^{22}$ In contrast, in India, the majority (64\%) of the coronavirus confirmed cases belong to the age group of $25-59$ years and only $15 \%$ of cases are aged $\geq 60$ years. ${ }^{23}$ In an ICMR study conducted by Gupta et al. reported that $82 \%$ COVID-19 cases overall were aged $>40$ years. ${ }^{24}$ India's age the structure is comparatively younger, and metropolitan cities comprise of more young population (labor/workforce). ${ }^{23}$ By analyzing the data (as of May $13,2020)$ provided by New York City Health, majority (48.7\%) of the coronavirus deaths were aged $\geq 75$ years following which $65-74$ years (24.09\%) and 45-64 years $(22.4 \%)$ were the more vulnerable age groups. ${ }^{[25]}$ Ningthoujam et al. reported that COVID-19 can affect all age groups irrespective of whether the people are young or old with a concluding statement "strong immunity is the key weapon to fight
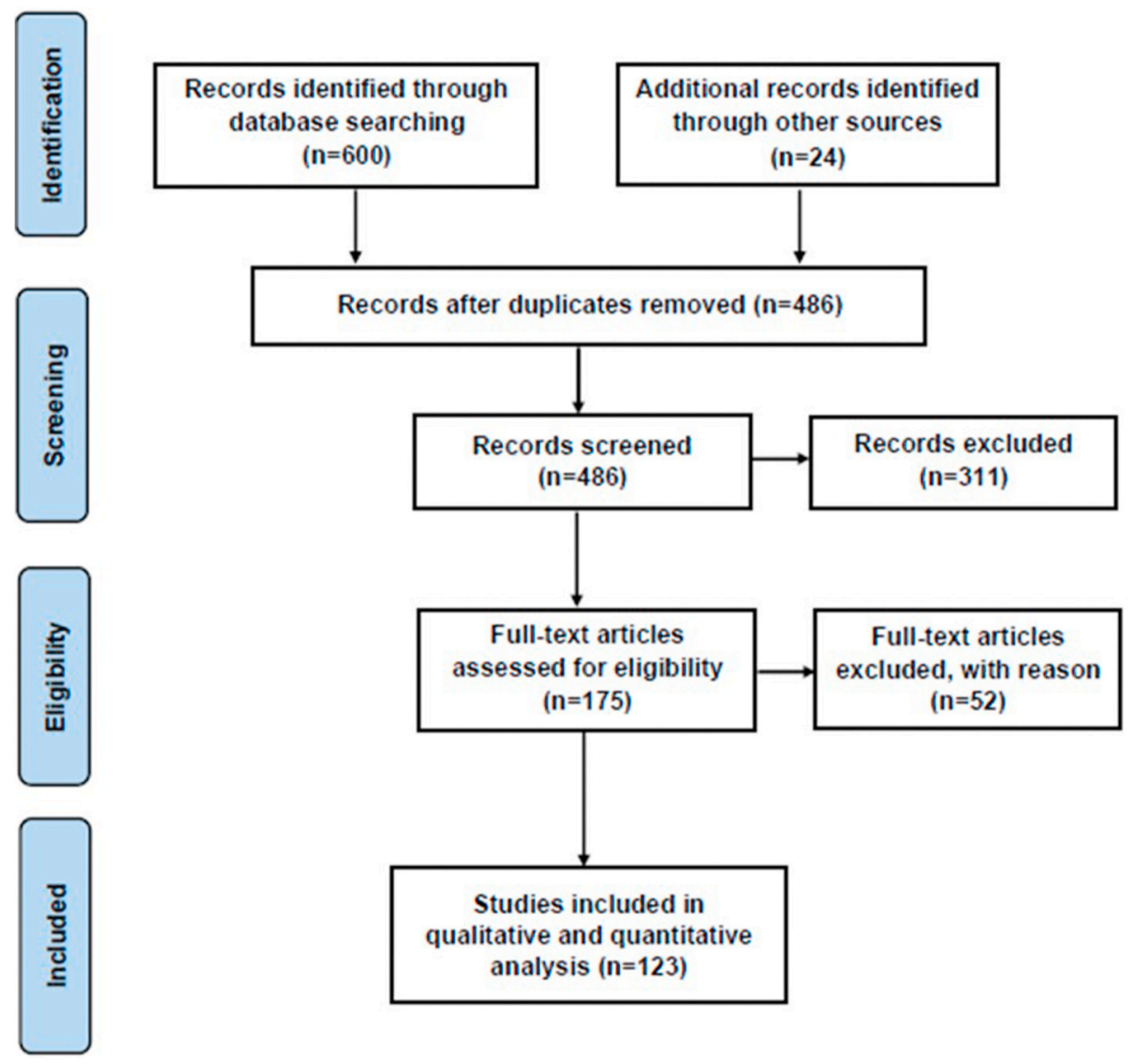

Fig. 1. PRISMA flow chart. 
against COVID-19". ${ }^{22}$

\section{Influence of latitude: an ignored effect?}

Casual exposure to sun ultraviolet rays (wavelengths 290-315 nm) results in the cutaneous production of cholecalciferol. ${ }^{26}$ During exposure to the sun, the UVB photons that enter the epidermis cause a photochemical transformation of 7-DHC (provitamin D3) to previtamin D3 and eventually cholecalciferol. ${ }^{27}$ The skin's ability to synthesize cholecalciferol is affected by earth's rotation around the sun (season-earth is closest to the sun in January and farthest from the sun in July) and its own axis (day and night). ${ }^{28}$ Atmospheric pollution attenuates UV solar radiation by absorbing and scattering sunlight before it reaches the earth's surface. ${ }^{29}$ Application of sunscreen agents with the sun protection factor (SPF) $\geq 15$ decreases the UVB penetration into skin epidermis by more than $95 \%$, thereby limiting the cutaneous production of previtamin $\mathrm{D}_{3}$. In addition, dress code, skin pigmentation, cloudy skies, latitude and altitude, amount of ozone, and time of day, which all limit the production of cholecalciferol by the skin. ${ }^{28}$ Occurrence of outbreak immediately after the winter season could have attributed to increased mortality. Meanwhile, seasonality of viral infections, especially URTIs, is associated with low 25(OH)D levels. For example, respiratory syncytial virus (RSV) infection is commonly observed during winter in temperate climates and the rainy season in tropical climates owing to low UVB doses. ${ }^{30,31}$

Many studies have documented and demonstrated the effect of season and latitude on the cutaneous synthesis of cholecalciferol. ${ }^{28}$ Grant et al. reported a strong negative correlation between CFR and UVB dose during the Spanish flu (1918 influenza pandemic). ${ }^{32}$ Countries at latitudes $<35^{\circ}$ North are more likely to receive adequate sunlight to maintain serum 25(OH)D levels during the winter. Based on available data on COVID-19, we calculated the CFR (from Dec 31, 2019 to Jun 14, $2020)$ for various countries $(n=120) .{ }^{33}$ It has been observed that mean CFR are relatively low in countries at latitudes $<35^{\circ}$ North $(2.41 \pm$ 2.10) compared to countries at latitudes $>35^{\circ}$ North $(3.99 \pm 3.23)$, which was statistically significant $(P<0.0001)$. Globally, there was a 2 -fold higher mortality rate among countries at latitudes $<35^{\circ}$ North than countries at latitudes $>35^{\circ}$ (OR: 1.6 95\% CI: 1.61-1.63; $P<$ 0.0001 ). Median and highest CFR observed in countries at latitudes $<35^{\circ}$ versus latitudes $>35^{\circ}$ were $1.89 \%$ and $8.02 \%$ (Mexico) versus $2.98 \%$ and $13.2 \%$ (France), respectively $(P=0.0028$; Mann-Whitney $U$ test). By Spearman's rank correlation analysis, a positive correlation was observed between CFR and latitude $(r=0.184 ; P=0.044)$. Our findings are in accordance with findings by Rhodes et al. ( $\mathrm{r}=0.53 ; P<0.0001$ as of Apr 15, 2020). Fig. 2 indicated an increasing CFR with increasing latitude.

Marik et al. calculated the CFR for each of the 50 states in the United States of America (USA) and reported that mortality is directly proportional to latitude. ${ }^{34}$ Marik et al. also reported that cumulative CFR was significantly higher for Northern states $>40^{\circ}$ latitude (6.0\%) compared to Southern States $(3.5 \% ; P<0.001) .{ }^{34}$ However, CFR is relatively low in few countries that lie above $50^{\circ}$ North (Nordic countries, Russia, Belarus, and Latvia), probably due to factors, such as low population density, adherence to social distancing, widespread usage of supplements, and racial makeup. ${ }^{35,36}$

\section{Influence of vitamin D supplementation in RTIs}

Majority of the studies indicate that preventive vitamin D supplementation during early spring seasons and winter can reduce the frequency and incidence of RTIs, especially seasonal influenza A. ${ }^{37}$ Manaseki-holland et al. reported that the risk of a recurrent attacks of community acquired pneumonia (CAP) was significantly lower in the children (1-36 months of age) who received a single oral vitamin D dose (of 100,000 IU). ${ }^{38}$ In a randomized controlled trial (RCT) conducted by Beig et al. reported that there was a significant reduction $(P<0.05)$ in the number of episodes of chronic cough and recurrent respiratory infections (RRIs) during 12 months follow-up after vitamin D supplementation (5000 IU per day for 3 months if serum Vitamin D levels less than $15 \mathrm{ng} / \mathrm{ml}$ and $400 \mathrm{IU}$ per day if vitamin D levels in the range of $15-20 \mathrm{ng} / \mathrm{ml}) .{ }^{39}$ A systematic review on five RCTs by Charan et al. reported that the reduction of frequent attacks of RTIs was significantly lower in the interventional group (vitamin D) compared to controls (OR: 0.58 95\% CI: $0.42-0.8 ; P=0.001) .{ }^{40}$ Bergman et al. reviewed 11 randomized placebo-controlled trials $(n=5660$; age ranging from six months to 75 years) and reported that the risk of RTIs was significantly lower with vitamin D supplementation (OR: 0.64 95\% CI: 0.49-0.84; $P$ $=0.0014){ }^{41}$ Martineau et al. in their meta-analysis (25 RCTs; $\mathrm{n}=10$, 933; age ranging from zero months to 95 years) reported that vitamin $D$ supplementation significantly reduces the risk of experiencing acute RTI by at least one (OR: $0.8895 \%$ CI: $0.81-0.96 ; P=0.003$ ). ${ }^{42}$ Currently, many RCTs are underway to test the effects of vitamin D on risk of acute RTIs. $^{43}$

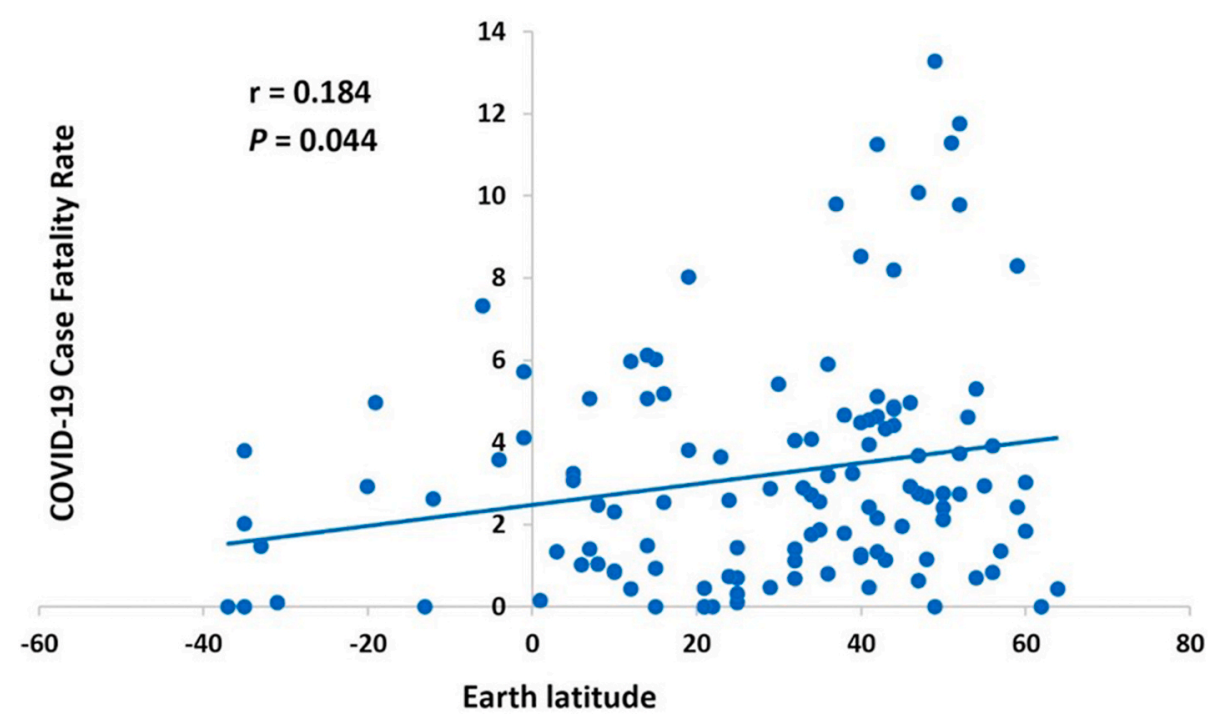

Fig. 2. Latitude dependent case fatality rate. 


\section{Does acute large doses of vitamin $\mathrm{D}$ would be beneficial?}

To date, different doses of vitamin $\mathrm{D}$ have been employed and still, it is not clear what dosage regimen would be beneficial. Manaseki-holland et al. evaluated whether the supplementation of a single large oral dosage of Vitamin D (100,000 IU) with antibiotics would reduce the risk of recurrent attacks and disease duration in children with CAP. ${ }^{38}$ They found that there was a significant reduction in the risk of a repeated episodes of CAP in the interventional group compared to placebo and concluded that a single large oral dose of vitamin D along with antibiotics can reduce the recurrence of pneumonia. ${ }^{38}$ Choudhary et al. reported that short-term oral vitamin D supplementation (1000 to $2000 \mathrm{IU}$ daily for five days) did not show beneficial effect on the clinical resolution of severe CAP. ${ }^{44}$ Manaseki-holland et al. conducted a randomized placebo-controlled trial (oral vitamin D 100,000 IU [n = 1524] and placebo [ $n=1522]$; once every three months for 18 months). The authors reported that quarterly bolus dosage of vitamin $\mathrm{D}$ has no beneficial effect in the reduction of incidence of CAP. ${ }^{44,45}$ Bergman et al. reported that prophylactic vitamin D (optimal dose: 1000 IU to 4000 IU per day) decreased the risk of developing RTIs (OR: 0.64 95\% CI: 0.49-0.84). ${ }^{41}$ The authors also found that the benefit was greatest in subjects living at latitudes $>40^{\circ} .{ }^{41}$ Van Groningen et al. conducted a dose comparison study on vitamin D deficient patients and intervened with solubilized cholecalciferol; 100,000 IU (25,000 IU biweekly for 8 weeks), 150,000 IU (25,000 IU every week for 6 weeks), and 200,000 IU (25,000 IU every week for 8 weeks). ${ }^{46}$ The authors observed that cumulative dose of 100 , $000 \mathrm{IU}, 150,000 \mathrm{IU}$, and 200,000 IU increased mean serum 25(OH)D levels by $29 \mathrm{nmol} / 1,43 \mathrm{nmol} / 1$, and $69 \mathrm{nmol} / 1$, respectively. The loading dose of cholecalciferol required to reach the target serum 25(OH)D level of $75 \mathrm{nmoL} / \mathrm{l}$ can be estimated as follows: ${ }^{46}$

Dose $(\mathrm{IU})=40 \times(75-$ serum $25[\mathrm{OH}] \mathrm{D}) \times$ Body weight

The National Heart, Lung, and Blood Institute (NHBLI) conducted an RCT to evaluate whether the single large dose of cholecalciferol (540,000 IU) would be beneficial in critically ill patients with severe vitamin D deficiency. But NHBLI failed to demonstrate any benefit from high dose of cholecalciferol. ${ }^{47}$ Many studies reported no adverse effects with high doses of vitamin D. ${ }^{46,48}$ Currently, large doses of vitamin D are not supported by clinical evidence and therefore, standard vitamin D dosage may be beneficial in providing adequate clinical response. ${ }^{34}$

\section{Influence of Vitamin-D in children}

LRTIs is the most common and leading cause of child mortality. ${ }^{49}$ Literature indicates that children have shown low susceptibility to infection by MERS-CoV, SARS-CoV-1, and SARS-CoV-2 compared to other viruses, such as RSV and influenza. ${ }^{50}$ According to the CDC report, fewer children were hospitalized $(5.7 \%-20 \%)$ and admitted to ICU $(0.58 \%-2.0 \%)$ compared to adults $(>30 \%)$; among them infants had a higher hospitalization rate (15\%-62\%) compared to children aged 1-17 years (4.1\%-14\%). ${ }^{51}$ A recent UNICEF report entitled "Lives Upended: How COVID-19 threatens the futures of 600 million South Asian Children" states that more than $8,80,000$ children could die due to COVID-related issues in the next 12 months; most deaths likely in India. ${ }^{52}$ The report also says that lack of nutritious diet to children (due to dwindling incomes and massive job loss) would be a predisposing factor. ${ }^{52} \mathrm{~A}$ well-established association has been found between vitamin $\mathrm{D}$ deficiency and respiratory illness from tuberculosis to RSV. ${ }^{53}$ Onwuneme et al. reported a high prevalence of low 25(OH)D levels $(<30$ $\mathrm{nmol} / \mathrm{L}$ [64\%] and $\leq 50 \mathrm{nmol} / \mathrm{L}$ [92\%]) in preterm infants which were significantly associated with acute respiratory illness in preterm infants immediately after birth; preterm infants with vitamin D insufficiency required increased resuscitation at delivery and assisted ventilation. ${ }^{54}$ Few recent observational studies have demonstrated that Vitamin D levels are significantly lower in children with latent TB and TB infection than in children without $\mathrm{TB}$ in the absence of any differences in dietary habits, sunlight exposure, or ethnic or social background. ${ }^{55-57}$ In developing countries, vitamin D or calcium deficiency may be potential predisposing factors for pneumonia in children under 5 years and vitamin $\mathrm{D}$ or calcium supplementation may lead to a significant reduction in CAP-related morbidity and mortality. ${ }^{58}$ In an Indian study on 150 children, a significant association was found between severe lower RTI and sub-clinical vitamin D deficiency. ${ }^{59}$ A Canadian study reported that mean serum 25(OH)D levels was significantly lower in LRTI subjects admitted to ICU $(49 \pm 24 \mathrm{nmol} / \mathrm{L})$ than subjects admitted to general ward $(87 \pm 39 \mathrm{nmol} / \mathrm{L}){ }^{60}$ Boosting children's immunity in the amidst COVID-19 is prerequisite and therefore, prophylactic measures and treatment guidelines deserve further research and attention.

\section{Vitamin D influence on underlying medical conditions versus COVID-19}

Patients with chronic medical conditions have a significantly higher risk of mortality from RTIs than healthy people. By analyzing the data (as of May 13, 2020) provided by New York City Health, patients with underlying conditions had a higher mortality rate $(75 \%)$ than patients without underlying conditions; among them $46 \%$ were aged $\geq 75$ years followed by $24.6 \%$ and $25.1 \%$ in age groups of $65-74$ years and $45-64$ years, respectively. ${ }^{25} \mathrm{~A}$ well-established association has been found between vitamin D deficiency and co-morbidities. ${ }^{61-63}$ Adequate serum 25(OH)D levels reduce the risk of many chronic illnesses, such as cardiovascular disease (CVD), Chronic kidney disease (CKD), chronic RTIs, hypertension, and diabetes mellitus (DM) ${ }^{64}$ A meta-analysis $(n=53$, 000 COVID-19 patients) reported that co-morbid conditions are risk factors for the severity of disease; hypertension (Relative risk [RR]: 4.49, 95\% CI: 3.7-5.4), DM (RR: 4.4, 95\% CI: 3.5-5.6), CVD (RR: 6.7, 95\% CI: 5.40-8.43), and CKD (OR: 6.01, 95\% CI: 2.2-16.5). ${ }^{65}$ Co-morbidities show an association with renin-angiotensin-aldosterone-system (RAAS), vitamin D status, and SARS-CoV-2. SARS-CoV-2 infection inhibits the counter regulatory activity to RAS via viral spike protein interaction with angiotensin converting enzyme2 (ACE2) on the cell surface. ${ }^{66}$ Thus, proinflammatory cytokines are entered into circulation and eventually leads to the progression of cardiovascular pathologies. ${ }^{65,66}$ Several studies reported that low serum 25(OH)D levels increased the plasma renin activity, RAS activity, and Ang II concentrations. ${ }^{67,68}$ Circulating 25(OH)D is inversely proportional to renin and thus, vitamin D acting as a negative RAS regulator. ${ }^{69}$ Increased secretion of renin in the early stages of vitamin D deficiency results in more fluid and salt reabsorption and a rise in vascular pressure. ${ }^{70}$ Hypertension and DM $(16.2 \%)$ were the most comorbidities seen in critically ill COVID patients. ${ }^{71,72}$ Majority of the corona deaths in China were due to CVS, chronic RTIs, DM, and hypertension. ${ }^{19}$ Hypertensive patients $(13 \pm 11$ and $13 \pm 10 \mathrm{ng} / \mathrm{ml}$ in males and females, respectively) had lower 25 $(\mathrm{OH}) \mathrm{D}$ concentrations compared to controls $(21 \pm 11$ and $20 \pm 11 \mathrm{ng} / \mathrm{ml}$ in males and females, respectively). ${ }^{73}$ Prediabetics had significantly lower 25(OH)D levels than controls as well as higher C-reactive protein as $25(\mathrm{OH}) \mathrm{D}$ levels decreased. ${ }^{74}$ In a large cohort study $(\mathrm{n}=3296)$, a significant rise in angiotensin II and plasma renin was observed with decreased 25(OH)D levels, but not with aldosterone levels. ${ }^{67}$ Most cases (92\%, 1657/1801) with metabolic syndrome had low serum 25(OH)D levels and $22.2 \%$ patients had very low $25(\mathrm{OH}) \mathrm{D}$ levels $(<25 \mathrm{nmol} / \mathrm{L}) .^{75}$ A bi-directional genetic approach ( 26 studies; $n=42,024$ ) showed that lower serum 25(OH)D levels lead to higher body mass index (BMI). ${ }^{65}$ Obesity could be a potential risk factor in patients with metabolic syndrome, coronary disorders, and hypertension since adipose tissue may lead to RAS overreaction. ${ }^{76,77}$ Qingxian et al. conducted a cohort study on 383 SARS-CoV-2 infected patients and reported that overweight (BMI: 24-27.9) and obese patients (BMI > 28) had $86 \%$ and $142 \%$ greater risk of developing pneumonia, respectively compared to normal weight patients. ${ }^{78}$ According to a federal report (CDC), patients with comorbidities, such as CVD and DM were six and twelve times more likely to hospitalize and die, respectively compared to healthy 
individuals infected with SARS-CoV-2; most commonly reported underlying conditions in SARS-CoV-2 infected patients were heart disease (32\%), DM (30\%) and chronic lung disease (18\%). ${ }^{79}$

\section{Recommendations}

Cholecalciferol supplementation should be started before winter to reach the target serum 25(OH)D range to reduce the risk of RTIs and COVID during winter. ${ }^{64}$ The half-life of calcitriol is about 15 days and that of calcidiol is between 13 and 15 days. ${ }^{80}$ Consequently, strict lockdown (longer time indoors and home quarantine) and there may be a risk of developing vitamin $\mathrm{D}$ deficiency. Although, the protective effect is directly proportional to serum $25(\mathrm{OH}) \mathrm{D}$ levels, the optimal $25(\mathrm{OH}) \mathrm{D}$ level should be in the range of $100-150 \mathrm{nmoL} / 1(40-60 \mathrm{ng} / \mathrm{ml}){ }^{81}$ Endocrine Society recommended that $1000-4000 \mathrm{IU} / \mathrm{d}$ of vitamin D would be beneficial for patients with any chronic illness to maintain a serum 25(OH)D levels $\geq 30 \mathrm{ng} / \mathrm{ml} .{ }^{82}$ On Mar 23, 2020, a former director of CDC, Dr. Tom Frieden proposed that vitamin D supplementation may reduce the risk of coronavirus infection. ${ }^{83}$ The U.S. Institute of Medicine reported that no adverse effects have been reported with supplementation of daily doses of vitamin $\mathrm{D}(<10,000 \mathrm{IU} / \mathrm{d}) .{ }^{84}$ Along with vitamin $\mathrm{D}$, supplementation of $250-500 \mathrm{mg} / \mathrm{d}$ magnesium is recommended because it acts as a cofactor for most enzymatic reactions and helps in the activation of vitamin D. ${ }^{85}$ Naturally, we can get abundant vitamin D from sunshine. ${ }^{28}$ Exposure of arms and legs ( $18 \%$ body surface) to sun rays between 11 a.m. and 2 p.m. until skin turns into slight pinkness is equivalent to supplementation of about 3600 IU cholecalciferol; weekly three times can provide adequate levels of vitamin D. ${ }^{28,86}$

Rigorous human clinical trials in different populations with different dosage regimens are urgently needed to check the association between vitamin D status and infection severity. Available evidence is very suggestive of protective and preventive effect of vitamin D against infections and COVID-19 pandemic. Now, it is the duty of governments to strengthen recommendations regarding nutritional supplementation (especially, immune-modulatory nutrients, such as vitamin D and C), particularly under quarantine and lockdown times.

\section{Funding/grant support}

This research received no specific grant from any funding agency in the public, commercial, or any profit sectors.

\section{Declaration of competing interest}

There are no conflicts of interest to declare.

\section{Acknowledgments}

We are thankful to statisticians, such as Pranamya, Pratik Bade, and Dr.Tulasi Reddy Kaliki for their statistical assistance.

\section{References}

1 Hart PH. Vitamin D supplementation, moderate sun exposure, and control of immune diseases. Discov Med. 2012;13:397-404.

2 Holick MF. Vitamin D deficiency. N Engl J Med. 2007;357:266-281.

3 Schwalfenberg GK. A review of the critical role of vitamin D in the functioning of the immune system and the clinical implications of vitamin D deficiency. Mol Nutr Food Res. 2011;55:96-108.

4 Liu PT, Stenger S, Li H, et al. Toll-like receptor triggering of a vitamin D-mediated human antimicrobial response. Science. 2006;311:1770-1773.

5 Adams JS, Ren S, Liu PT, et al. Vitamin d-directed rheostatic regulation of monocyte antibacterial responses. J Immunol. 2009;182:4289-4295.

6 Laaksi I. Vitamin D and respiratory infection in adults. Proc Nutr Soc. 2012;71:90-97.

7 Herr C, Shaykhiev R, Bals R. The role of cathelicidin and defensins in pulmonary inflammatory diseases. Expet Opin Biol Ther. 2007;7:1449-1461.

8 Barlow PG, Svoboda P, Mackellar A, et al. Antiviral activity and increased host defense against influenza infection elicited by the human cathelicidin LL-37. PloS One. 2011;6, e25333.
9 Gombart AF, Pierre A, Maggini S. A review of micronutrients and the immune System-Working in harmony to reduce the risk of infection. Nutrients. 2020;12:236.

10 Esposito S, Baggi E, Bianchini S, Marchisio P, Principi N. Role of vitamin D in children with respiratory tract infection. Int J Immunopathol Pharmacol. 2013;26: $1-13$.

11 Huang C, Wang Y, Li X, et al. Clinical features of patients infected with 2019 novel coronavirus in Wuhan, China. Lancet. 2020;395:497-506.

12 Lemire JM, Adams JS, Kermani-Arab VA, Bakke AC, Sakai R, Jordan SC. 1, 25Dihydroxyvitamin D3 suppresses human T helper/inducer lymphocyte activity in vitro. J Immunol. 1985;134:3032-3035.

13 Theron M, Huang KJ, Chen YW, Liu CC, Lei HY. A probable role for IFN- $\gamma$ in the development of a lung immunopathology in SARS. Cytokine. 2005:32:30-38.

14 Mahallawi WH, Khabour OF, Zhang Q, Makhdoum HM, Suliman BA. MERS-CoV infection in humans is associated with a pro-inflammatory Th1 and Th17 cytokine profile. Cytokine. 2018;104:8-13.

15 Wong CK, Lam CW, Wu AK, et al. Plasma inflammatory cytokines and chemokines in severe acute respiratory syndrome. Clin Exp Immunol. 2004;136:95-103.

16 Vásárhelyi B, Sátori A, Olajos F, Szabó A, Bekő G. Low vitamin D levels among patients at Semmelweis University: retrospective analysis during a one-year period. Orv Hetil. 2011;152:1272-1277.

17 MacLaughlin J, Holick MF. Aging decreases the capacity of human skin to produce vitamin D3. Clin Invest. 1985;76:1536-1538.

18 Gröber U, Kisters K. Influence of drugs on vitamin D and calcium metabolism. Dermatoendocrinol. 2012;4:158-166.

19 Zhong hua, Liu Xing, Xue Bing, Zhi Za. The epidemiological characteristics of an outbreak of 2019 novel coronavirus diseases (COVID-19) in China. Novel CP. 2020; 41:145-151.

20 Daneshkhah A, Eshein A, Subramanian H. The role of vitamin D in suppressing cytokine storm of COVID-19 patients and associated mortality. MedRxiv. 2020.

21 Bulut C, Kato Y. Epidemiology of COVID-19. Turk J Med Sci. 2020;50:563-570.

22 Ningthoujam R, Khomdram D. WHO statement-"Older people are at highest risk from COVID-19": should the hypothesis be corroborated or rejected? Med Hypotheses. 2020;16:109896.

23 Dhillon P, Sampurna Kundu CS, Ram U, Dwivedi LK, Yadav S, Unisa S. Case-fatality ratio and recovery rate of COVID-19: scenario of most affected countries and Indian states. IIPS Analytical Series on Covid 19 IIPS Analytical Series on Covid. 2020;19. https://doi.org/10.13140/RG.2.2.25447.68000.

24 Gupta N, Praharaj I, Bhatnagar T, et al. Severe acute respiratory illness surveillance for coronavirus disease 2019, India, 2020. Indian J Med Res. 2020;151:236.

25 New York City Health. Coronavirus Disease 2019 (COVID-19); 2020. Available from: https://www1.nyc.gov/assets/doh/downloads/pdf/imm/covid-19-daily-datasummary-deaths-05132020-1.pdf . Accessed June 16, 2020.

26 Holick MF. Vitamin D requirements for the elderly. Clin Nutr. 1986;5:121-129.

27 Holick MF. Vitamin D: a millenium perspective. J Cell Biochem. 2003;88:296-307.

28 Harinarayan CV, Holick MF, Prasad UV, Vani PS, Himabindu G. Vitamin D status and sun exposure in India. Dermatoendocrinol. 2013;5:130-141.

29 Li X, Wagner F, Peng W, Yang J, Mauzerall DL. Reduction of solar photovoltaic resources due to air pollution in China. Proc Natl Acad Sci Unit States Am. 2017;114: $11867-11872$.

30 Nam HH, Ison MG. Respiratory syncytial virus infection in adults. BMJ. 2019;366: 15021.

31 Paynter S, Ware RS, Sly PD, Weinstein P, Williams G. Respiratory syncytial virus seasonality in tropical Australia. Aust N Z J Publ Health. 2015;39:8-10.

32 Grant WB, Giovannucci E. The possible roles of solar ultraviolet-B radiation and vitamin D in reducing case fatality rates from the 1918-1919 influenza pandemic in the United States. Dermatoendocrinol. 2009;1:215-219.

33 Worldometer. COVID-19 CORONAVIRUS PANDEMIC. Available from https://www. worldometers.info/coronavirus/; 2020. Accessed June 16, 2020.

34 Marik PE, Kory P, Varon J. Does vitamin D status impact mortality from SARS-CoV-2 infection? Med Drug Discov. 2020;6:100041.

35 Lips P, Cashman KD, Lamberg-Allardt C, et al. Current vitamin D status in European and Middle East countries and strategies to prevent vitamin D deficiency: a position statement of the European Calcified Tissue Society. Eur J Endocrinol. 2019;180: 23-54.

36 Rhodes JM, Subramanian S, Laird E, Kenny RA. Low population mortality from COVID-19 in countries south of latitude 35 degrees North supports vitamin D as a factor determining severity. Aliment Pharmacol Ther. 2020;51:1434-1437.

37 Urashima M, Segawa T, Okazaki M, Kurihara M, Wada Y, Ida H. Randomized trial of vitamin D supplementation to prevent seasonal influenza A in schoolchildren. Am J Clin Nutr. 2010;91:1255-1260.

38 Manaseki-Holland S, Qader G, Isaq Masher M, et al. Effects of vitamin D supplementation to children diagnosed with pneumonia in Kabul: a randomised controlled trial. Trop Med Int Health. 2010;15:1148-1155.

39 Beig FK, Sachdeva S, Khan MA. Vitamin D deficiency and potentially modifiable respiratory morbidity and mortality among children: food for thought. SF J Pediatr Care and Neonatol. 2019;1:1001.

40 Charan J, Goyal JP, Saxena D, Yadav P. Vitamin D for prevention of respiratory tract infections: a systematic review and meta-analysis. J Pharmacol Pharmacother. 2012;3: 300-303.

41 Bergman P, Lindh AU, Bjorkhem-Bergman L, Lindh JD. Vitamin D and respiratory tract infections: a systematic review and meta-analysis of randomized controlled trials. PloS One. 2013;8, e65835.

42 Martineau AR, Jolliffe DA, Hooper RL, et al. Vitamin D supplementation to prevent acute respiratory tract infections: systematic review and meta-analysis of individual participant data. BMJ. 2017;356:16583. 
43 World Health Organization. International clinical trials registry platform. Available from:https://apps.who.int/trialsearch/nutrition.aspx?Title=respiratory\%20infect on\%20and\%20vitamin\%20D\%20and\%20children\%20 . Accessed June 16, 2020.

44 Choudhary N, Gupta P. Vitamin D supplementation for severe pneumonia: a randomized controlled trial. Indian Pediatr. 2011:49:449-454.

45 Manaseki-Holland S, MaroofZ Bruce J, Mughal MZ, et al. Effect on the incidence of pneumonia of vitamin D supplementation by quarterly bolus dose to infants in Kabul: a randomised controlled superiority trial. Lancet. 2012;379:1419-1427.

46 Van Groningen L, Opdenoordt S, van Sorge A, Telting D, Giesen A, de Boer H. Cholecalciferol loading dose guideline for vitamin D-deficient adults. Eur $J$ Endocrinol. 2010;162:805-811.

47 National Heart Lung, Blood Institute PETAL Clinical Trials Network. Early high-dose Vitamin D3 for critically ill, Vitamin D-deficient patients. N Engl J Med. 2019;381: 2529-2540.

48 Charoenngam N, Shirvani A, Kalajian TA, Song A, Holick MF. The effect of various doses of oral vitamin D3 supplementation on gut microbiota in healthy adults: a randomized, double-blinded, dose-response study. Anticancer Res. 2020;40:551-556.

49 Ramani VK, Pattankar J, Puttahonnappa SK. Acute respiratory infections among under-five age group children at urban slums of gulbarga city: a longitudinal study. J Clin Diagn Res. 2016;10:LC08-LC13.

50 Chen J. Pathogenicity and transmissibility of $2019-\mathrm{nCoV}$ - a quick overview and comparison with other emerging viruses. Chen J Microbes Infect. 2020;22:69-71.

51 CDC COVID-19 Response Team. Coronavirus disease 2019 in children - United States, february 12-april 2, 2020. MMWR Morb Mortal Wkly Rep. 2020. https://doi.org/ 10.15585/mmwr.mm6914e4.

52 UNICEF. Lives upended: How COVID-19 threatens the futures of 600 million South asian children. Available from https://www.unicef.org/rosa/lives-upended; 2020. Accessed June 26, 2020.

53 Maxwell CS, Carbone ET, Wood RJ. Better newborn vitamin D status lowers RSVassociated bronchiolitis in infants. Nutr Rev. 2012;70:548-552.

54 Onwuneme C, Martin F, McCarthy R, et al. The association of vitamin D status with acute respiratory morbidity in preterm infants. J Pediatr. 2015;166:1175-1180.

55 Sita-Lumsden A, Lapthorn G, Swaminathan R, Milburn HJ. Reactivation of tuberculosis and vitamin D deficiency: the contribution of diet and exposure to sunlight. Thorax. 2007;62:1003-1007.

56 Williams B, Williams AJ, Anderson ST. Vitamin D deficiency and insufficiency in children with tuberculosis. Pediatr Infect Dis J. 2008;27:941-942.

57 Gray K, Wood N, Gunasekera H, et al. Vitamin D and tuberculosis status in refugee children. Pediatr Infect Dis J. 2012;31:521-523.

58 Muhe L, Lulseged S, Mason KE, Simoes EA. Case-control study of the role of nutritional rickets in the risk of developing pneumonia in Ethiopian children. Lancet. 1997;349:1801-1804.

59 Wayse V, Yousafzail A, Mogale K, Filteau S. Association of subclinical vitamin D deficiency with severe acute lower respiratory infection in Indian children under 5 years. Eur J Clin Nutr. 2004;58:563-567.

60 McNally JD, Leis K, Matheson LA, Karuananyake C, Sankaran K, Rosenberg AM. Vitamin D deficiency in young children with severe acute lower respiratory infection. Pediatr Pulmono1. 2009;44:981-988.

61 Kunutsor SK, Apekey TA, Steur M. Vitamin D and risk of future hypertension: metaanalysis of 283,537 participants. Eur J Epidemiol. 2013;28:205-221.

62 Mauss D, Jarczok MN, Hoffmann K, Thomas GN, Joachim E, Fischer JE. Association of vitamin D levels with type 2 diabetes in older working adults. Int J Med Sci. 2015; 12:362-368.

63 Yao Y, Zhu L, He L, et al. A meta-analysis of the relationship between vitamin D deficiency and obesity. Int J Clin Exp Med. 2015;8:14977-14984.

64 Grant WB, Lahore H, McDonnell SL, et al. Evidence that vitamin D supplementation could reduce risk of influenza and COVID-19 infections and deaths. Nutrients. 2020 12:988.
65 Biesalski HK. Vitamin D deficiency and co-morbidities in COVID-19 patients-A fatal relationship? NFS Journal. 2020;20:10-21.

66 Wang K, Gheblawi M, Oudir GY. Angiotensin converting enzyme 2: a double-edged sword. Circulation. 2020.

67 Tomaschitz A, Pilz S, Ritz E, et al. Independent association between 1,25-dihydroxyvitamin $\mathrm{D}, 25$-hydroxyvitamin $\mathrm{D}$ and the renin-angiotensin system: the ludwigshafen risk and cardiovascular health (LURIC) study. Clin Chim Acta. 2010; 411:1354-1360.

68 Vaidya A, Forman JP, Hopkins PN, Seely EW, Williams JS. 25-hydroxyvitamin D is associated with plasma renin activity and the pressor response to dietary sodium intake in Caucasians. J Renin-Angiotensin-Aldosterone Syst JRAAS. 2011;12:311-319.

69 Yuan W, Pan W, Kong J, et al. 1, 25-dihydroxyvitamin D3 suppresses renin gene transcription by blocking the activity of the cyclic AMP response element in the renin gene promoter. J Biol Chem. 2007;282:29821-29830.

70 Kong J, Zhang Z, Li D, et al. Loss of vitamin D receptor produces polyuria by increasing thirst. J Am Soc Nephrol. 2008;19:2396-2405.

71 Xie J, Tong Z, Guan X, Du B, Qiu H. Clinical characteristics of patients who died of coronavirus disease 2019 in China. JAMA Netw Open. 2020;3, e205619.

72 Guan WJ, Ni ZY, Hu Y, et al. Clinical characteristics of coronavirus disease in China. N Engl J Med. 2020;382:1708-1720.

73 NaghShtaBrizi B, Borzouei S, BigvaNd P, ali SeifraBiei M. Evaluation of the relationship between serum 25-hydroxy vitamin D and hypertension in hamadan, Iran-A case control study. J Clin Diagn Res. 2017:11:LC01-LC03.

74 Zhang M, Gao Y, Tian L, et al. Association of serum 25-hydroxyvitamin D3 with adipokines and inflammatory marker in persons with prediabetes mellitus. Clin Chim Acta. 2017:468:152-158.

75 Thomas GN, ó Hartaigh B, Bosch JA, et al. Vitamin D levels predict all-cause and cardiovascular disease mortality in subjects with the metabolic syndrome: the Ludwigshafen Risk and Cardiovascular Health (LURIC) Study. Diabetes Care. 2012; 35:1158-1164.

76 Cheng S, Massaro JM, Fox CS, et al. Adiposity, cardiometabolic risk, and vitamin D status: the framingham heart study. Diabetes. 2010;59:242-248.

77 Hsueh WA, Wyne K. Renin-angiotensin-aldosterone system in diabetes and hypertension. J Clin Hypertens. 2011;13:224-237.

78 Cai Q, Chen F, Wang T, et al. Obesity and COVID-19 severity in a designated hospital in Shenzhen, China. Diabetes Care. 2020, dc200576.

79 Sun Lena H. Patients with underlying conditions were 12 times as likely to die of covid-19 as otherwise healthy people, CDC finds. The Washington Post. Available from: https://www.washingtonpost.com/health/2020/06/15/patients-with-underl ying-conditions-were-12-times-more-likely-die-covid-19-than-otherwise-healthypeople-cdc-finds/; 2020. Accessed June 27, 2020.

80 Jones KS, Assar S, Harnpanich D, et al. $25(\mathrm{OH})$ D2 half-life is shorter than $25(\mathrm{OH})$ D3 half-life and is influenced by DBP concentration and genotype. $J$ Clin Endocrinol Metab. 2014;99:3373-3381.

81 Heaney RP, Davies KM, Chen TC, Holick MF, Barger-Lux MJ. Human serum 25hydroxycholecalciferol response to extended oral dosing with cholecalciferol. Am J Clin Nutr. 2003;77:204-210.

82 Holick MF, Binkley NC, Bischoff-Ferrari HA, et al. Evaluation, treatment, and prevention of vitamin D deficiency: an Endocrine Society clinical practice guideline. J Clin Endocrinol Metab. 2011;96:1911-1930.

83 Available from: https://www.foxnews.com/opinion/former-cdc-chief-tom-friedencoronavirus-risk-may-be-reduced-with-vitamin-d. Accessed June 27, 2020.

84 Ross AC, Manson JE, Abrams SA, et al. The 2011 report on dietary reference intakes for calcium and vitamin D from the Institute of Medicine: what clinicians need to know. J Clin Endocrinol Metab. 2011;96:53-58.

85 Uwitonze AM, Razzaque MS. Role of magnesium in vitamin D activation and function. J Am Osteopath Assoc. 2018;118:181-189.

86 Holick MF. Vitamin D: the underappreciated D-lightful hormone that is important for skeletal and cellular health. Curr Opin Endocrinol Diabetes. 2002;9:87-98. 